\title{
The Challenges of Precepting Undergraduate Nursing Students in Malawi
}

\author{
Lucky Mhango ${ }^{1,2}$ \\ Masumbuko Baluwa' \\ Ellen Chirwa ${ }^{2}$ \\ 'Mzuzu University, Department of \\ Nursing and Midwifery, Mzuzu, Malawi; \\ ${ }^{2}$ University of Malawi, Kamuzu College of \\ Nursing, Blantyre, Malawi
}

Correspondence: Lucky Mhango

Mzuzu University, Department of Nursing and Midwifery, Mzuzu, Malawi

Tel +265995421648

Fax +2651320568

Email mhango20I4lucky@kcn.unima.mw
Purpose: Malawi trains registered nurses as clinical preceptors to facilitate quality clinical teaching to nursing students. The concept of preceptorship is new in Malawi, and as such data about its contribution and challenges are scanty. It is for this reason that this study was undertaken to explore the challenges that preceptors face as they teach students.

Methods: This exploratory-descriptive qualitative study was conducted at Malawi's four major referral hospitals utilised by nursing training institutions as clinical sites. A sample of 12 participants was purposively selected to provide data regarding challenges encountered during preceptorship activities. In-depth interviews were conducted in order to collect data on challenges experienced by these facilitators. The data were later categorised and analysed into themes.

Results: From the analysed data, three key themes emerged including preceptorship as timeconsuming, lack of support from faculty members and lack of teamwork among preceptors. Conclusion: The study concluded that preceptors face several challenges that affect the quality of clinical teaching. The study recommends that there should be an improvement in the working relationship among those involved in clinical teaching to enhance clinical learning experiences among student nurses. It also recommends that more registered nurses should be trained as preceptors to improve the student-preceptor ratio.

Keywords: preceptorship, preceptor, clinical teaching, nursing, clinical learning

\section{Introduction}

Clinical teaching is an essential component in the education of undergraduate nursing students as it helps in the transferring and actualization of theoretical knowledge into practice. This is a component of the nurse training programme that enhances professional growth among student nurses by providing them with opportunities to apply theoretical knowledge into practice. ${ }^{1}$ In order to achieve effective clinical teaching and learning experiences, literature recommends the use of clinical instructors to guide and assist students during their clinical experiences. ${ }^{2}$ For this reason, educational institutions rely on registered nurses practicing in the specific placement area to take the role of clinical instructors for students allocated within their unit. However, it has been argued that while on-field nurses are a better option for providing practical support to students as expert clinicians, not all of them are educators hence the need to provide them with educational support that

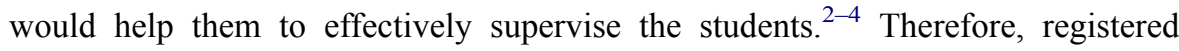
nurses who are earmarked for the provision of clinical instructor roles are trained for these preceptorship roles. ${ }^{1}$ 
Malawi adopted the preceptorship model for clinical education in 2009 in order to assist undergraduate nursing students during clinical experiences. Thus, experienced registered nurses, working in the hospitals, were trained as preceptors for a period of six weeks, and were expected to teach and guide undergraduate nursing students allocated to their departments in addition to their daily patient care duties. These additional tasks were given to these nurses against the background that Malawi has the highest nursepatient ratios as well as high disease burden which could potentially overstretch the challenges nurses already face. ${ }^{5}$ In other countries, literature ${ }^{1,6}$ has demonstrated that preceptors face several challenges when executing their preceptorship roles. For example, there have been cases of role confusion amongst the majority of practicing nurses hired for preceptorship roles. ${ }^{7,8}$ On this, preceptors feel that their role of providing nursing care to patients was overtaken by preceptorship role. Further, there is usually lack of support from nursing faculty members making it difficult for the preceptorship goals to be met. ${ }^{4}$ It has been revealed that faculty members were rarely present in the clinical sites, and if at all present, they briefly stayed in the ward without meeting the preceptors, and this complicated the preceptor's role. ${ }^{8}$ In addition to this, preceptor's over-workload, lack of support from peers, and overall lack of support from the nursing faculty members negatively affected the role of the preceptors. ${ }^{1}$ Challenges such as overworking and lack of support from training institutions and their own colleagues often led to fatigue, burnout and demotivation. ${ }^{9}$ Besides these, some studies have argued that increased workload among preceptors will often militate against effective preceptorship. $^{10}$

Factually, clinical teaching and guidance is merely an additional task to the preceptor's day-to-day activities such as patient care and administration. It is usually challenging therefore to combine and balance clinical teaching with patient care duties especially when the ward has many students and critically ill patients all requiring attention of the preceptor. ${ }^{11}$ Obviously, preceptors need to fulfil these equally important tasks by making sure that preceptorship activities are executed while simultaneously serving the patients equally well and in time. It is then the case that preceptorships programmes have often been reported as time-consuming activities. ${ }^{4,11}$ In some occasions, preceptors have often left other fellow clinical staff members to do the core ward activities while they spend their time teaching and supervising students, which has often led to conflicts and disagreement. ${ }^{10}$ This has, in turn, created stress among preceptors who think that their role as preceptors is not appreciated and often misunderstood by those around them.

While many studies ${ }^{1,6,7}$ have sought to explore challenges of teaching and guiding nursing students in wellresourced contexts, there have been limited studies that have focused on resource constrained contexts leading to lack of data that can be utilised by both researchers and policymakers. There was a need for a study like this one that would identify critical challenges that confront the preceptorship programme within a resource constrained context such as Malawi. A previous study from student's perspective revealed that preceptorship improved their confidence in clinical practice. ${ }^{12}$ However, the preceptorship model as it is implemented in Malawi has not been studied and therefore not much was known about the challenges of this clinical teaching strategy. The main aim of this study therefore was to explore the challenges of precepting undergraduate nursing students in Malawi.

\section{Methods}

\section{Study Design}

An exploratory-descriptive qualitative research design was employed in this study conducted from July 2016 to December 2017. Hunter, McCallum and Howes ${ }^{13}$ assert that exploratory-descriptive qualitative design is an appropriate research design to study areas within healthcare practice that have previously received little or no attention. Preceptorship is a new clinical teaching strategy in Malawi.

\section{Study Setting}

The study was conducted in four major tertiary hospitals in Malawi. The hospitals are located in the four major cities of Malawi, namely, Blantyre, Lilongwe, Mzuzu and Zomba. Further, these are major teaching hospitals for different health-related professions from all Malawian universities. Some registered nurses from these facilities were trained as preceptors for undergraduate nursing students among their members of staff.

\section{Sampling and Selection of Study Participants}

The target population included all preceptors at the referral hospitals and the total estimated from records of preceptors was thirty-three $(n=33)$. The researcher recruited a sample of twelve (12) participants through purposive 
sampling technique. Variations such as registered nurse qualification and years of experience as a preceptor were considered during the recruitment process. There were six male and six female participants. By purposive sampling, it implies that participants were recruited based on certain necessary characteristics such as experience as a preceptor and willingness to take part in the study. ${ }^{14}$ In addition, sample sizes of 10 to 25 participants are considered appropriate for qualitative data. ${ }^{15,16}$ According to Polit and Beck, ${ }^{16}$ samples can even be fewer than 50 . The adequacy of the sample size is always determined by the principle of data saturation. In this study, a sample of 12 from a target of 33 participants achieved saturation and therefore was deemed to be adequate. Participants were recruited based on the following criteria: working as a preceptor for three years or more and willingness to participate in the study. The assumption was that such preceptors had worked for enough time that introduced and afforded them enough experiences regarding the contributions and challenges of this programme. The researcher approached the prospective participants and explained to them the study procedures. Those who met the criteria and were willing to participate were given an information sheet which contained detailed information about the study, and informed consent was sought from them which included the possibility for publication of their responses anonymously. None of the participants who were approached declined to participate.

\section{Data Collection}

The researcher conducted three face-to-face individual interviews lasting sixty minutes at each of the study sites $(n=12)$. An interview guide comprising open-ended questions was utilised. The guide was formulated by the researcher with reference to the roles, experiences and challenges of preceptorship. It was thereafter reviewed by an independent researcher and expert in preceptorship for content and the feedback was considered in the final guide. During the interviews, special rooms were arranged to maintain privacy and confidentiality. An audio recorder was used to capture and store data that were provided. Field notes were taken to capture all elements of the interview that would have contributed to or affected the findings.

A 32-item checklist for explicit and comprehensive reporting of qualitative studies was utilised in order to report important aspects of the research team, study methods, context of the study, findings, analysis and interpretations (Tong, Sainsbury \& Craig, 2007). ${ }^{17}$

\section{Data Management and Analysis}

Immediately after data collection, the researcher transcribed the recorded data verbatim. The recorded information, field notes, and transcripts were kept in a lockable cupboard accessible by the principal investigator only. A computer with the data had a password known by the principal investigator.

Data were analysed thematically following Braun and Clarke $^{18}$ six-phase guide framework. This involves working with data, organising and breaking them into manageable units, synthesising and searching for patterns, discovering what was important and what was to be learned. This was done to reduce and display the data, to verify them and draw a conclusion. ${ }^{13}$ Audiotape recordings of the individual interviews were transcribed verbatim for the purpose of analysing the data.

Trustworthiness was achieved through an interactive approach and use of language that was well understood by all the participants. The interviews were audio recorded and transcribed verbatim to promote data credibility and trust. Dependability was achieved through audit trail which involved keeping detailed information regarding methodology, audio recording, interview notes and data collection instruments. To determine confirmability, the researcher continuously reflected on his own value bracketing of feeling and beliefs in preceptorship to avoid prior assumptions. An expert well versed in qualitative research reviewed the analysis decisions and validated the themes that were formulated. Transferability was facilitated through purposive sampling and use of a thick description of the enquiry.

\section{Ethical Considerations}

Permission to conduct the study was granted by the College of Medicine Research and Ethics Committee (COMREC) Certificate P.11/16/2015.

Permission was also sought from the four tertiary Hospital Management and individual heads of departments where the participants were drawn. All the participants were assured that their participation in the study was voluntary and written informed consent was obtained prior to the interviews and discussions. Further to that consent was sought on the possibility for publication of their responses anonymously to which all of them were in agreement. Voluntary participation and informed consent 
ensured that the study complied with ethical requirements. Additionally, the researchers ensured the research participants that they could withdraw at any time without facing reprimands. Confidentiality and anonymity of the participants were observed by conducting interviews in private places and using codes for identification of the participants. The participants were informed that the information they provided would be used to improve services.

\section{Results}

\section{Demographic Characteristics of Respondents}

There were 12 participants, of which six were female and six were male. Their work experience ranged from 3 to 5 years in preceptorship. All the participants were registered nurses with a bachelor's degree (Table 1).

\section{Emerged Themes}

The findings revealed that preceptors experience several challenges in the course of guiding and teaching nursing students. Three themes emerged from the data, including time consuming, lack of support from faculty members and lack of teamwork. These themes portrayed the major challenges of the preceptors as they executed their preceptorship roles.

\section{Time Consuming}

Preceptors viewed their preceptorship roles as time consuming and a disturbance to their core function of patient care. In support of this, one participant argued:

Being a preceptor is time consuming because I have different other roles to partake. I am the ward manager, I have to look after the patients, I have to look after the students and so on. So, there are things taking place at once. A student wants this, a patient wants that, my bosses need this. (participant 001)

Table I Demographic Characteristics of Respondents

\begin{tabular}{|l|c|}
\hline Variable & Finding \\
\hline Gender Male & 6 \\
Female & 6 \\
\hline Registered nurse qualification & \\
Bachelor's degree & 12 \\
\hline Post preceptorship training experience & \\
3 years & 2 \\
4 years & 6 \\
5 years & 4 \\
\hline
\end{tabular}

The above sentiments were corroborated by another participant who echoed:

Like in this ward, I am the in-charge, and I am involved in so many roles ... For example, when it comes to ward administration and other responsibilities, all of these falls under me such that time factor becomes a problem. (participant 004)

It was clear that the issue of time prevented many preceptors from having adequate interactions with the student nurses. It is also clear that these preceptors were unable to fulfil their obligations effectively due to the many roles that they had under their care as expressed in this statement:

\begin{abstract}
As a care provider, patients need you to provide them with the required care ... and you have students to teach, some of them may even be coming for clinical practice for the first time and there would be inadequate time to interact with them. Even on staffing, you may be alone at the facility, therefore you are in a dilemma on whether to concentrate on assisting the students or carry out the duty of patient care? (participant 010)
\end{abstract}

\section{Lack of Support from Faculty Members}

Some preceptors reported infrequent or lack of students' supervision, lack of involvement during clinical teaching as well as evaluation and assessment. For example, one of them said this regarding the faculty members and their conduct.

Frankly speaking we don't do most of the things together. The faculty members in most cases just come and do whatever they want to do with the students without seeing us, and off they go. We have ever had meetings on this but still more they would not work with us the preceptors. (participant 004)

Furthermore, preceptors expressed that some faculty members did not recognize them as preceptors, and this made their work to be challenging and questionable. Some of the participants expected that when the faculty members came, they would work with them when observing the students. This view was corroborated by one of the participants who asserted:

One of the challenges we face is lack of coordination between us and the colleges where the students come from. We don't work hand in hand with the faculty members. So, because we do not do that, there are challenges especially when a student misbehaves or is not doing well. (participant 007) 
Other preceptors felt that they were not recognised by faculty members as noted from the following statement:

I feel that students recognise me but there is no recognition from the faculty members and when they come to work with the students, they just go straight to them. This is something that encourages the students to look down upon us as preceptors. (participant 003)

Some preceptors expressed lack of follow-up initiatives in the clinical area by the faculty members. They felt that colleges left the responsibility of clinical teaching as well as supervision of the students in the hands of the preceptors. One of the participants said:

Most of the times they would say we have come with the students .... They would not come to follow up on them but left all the responsibilities to us. I think what we need to do is to work closely together with them throughout the time the students are allocated in the clinical area and they need to be coming regularly to find out how the students are progressing. (participant 006)

\section{Lack of Teamwork}

Some preceptors reported lack of teamwork which often led to conflict with their colleagues. They argued that when a trained preceptor is absent due to other reasons, the colleagues who are not formally trained as preceptors were not willing to stand in for them. This led to disruption or cancellation of the preceptorship sessions leading to gaps and poor-quality clinical experiences. This was supported by one of the participants who said:

The other challenge is that some of the qualified staff who have not been trained as preceptors don't want to take part in the teaching of the students may be because they feel like, the preceptors who went for the preceptorship training benefitted financially so they cannot teach on their behalf. So, if you as a preceptor are not around for the students ... and the other members of staff were asked to assist you, they would say no, wait for the preceptor. (participant 005)

Participants supported this by stating that challenges of being a preceptor included those from fellow staff in the sense that when they are asked to assist the students with teaching, they usually react negatively thinking that maybe the preceptors were just absconding their core duty of patient care. Likewise, due to shortage of preceptors, the preceptors felt that following up of students in the clinical areas was problematic. One of them said:
Another challenge we face is that of few preceptors. For example, I am the only one in this ward and I find it tough to find time to adequately work with each student due to large numbers allocated to this ward. Even if one looks at the ratio between the preceptors and the number of students, it is just too huge. Therefore, we need more preceptor trainings. (participant 007)

\section{Discussion}

The study aimed to explore the challenges of precepting undergraduate nursing students in Malawi. The results indicate that preceptors encountered several challenges as they executed their preceptorship roles. They perceived preceptorship roles to be time consuming mainly due to multiple roles they hold such as being a preceptor and a healthcare provider. They expressed that there were moments they would be required to provide healthcare services to patients and do managerial work for their wards, at the same time, teach students. This scenario made the preceptors feel that their preceptorship role was overtaking their patient care as well as managerial roles, which created work overload on their part. They felt dissatisfied with the time they had to spend supporting students. This is in agreement with Broadbent et $\mathrm{al}^{7}$ who reported in their study that preceptors were not satisfied with the time they had to support students whilst fulfilling their roles as healthcare providers. Similarly, literature has indicated that increased workload made precepting cumbersome and time consuming. ${ }^{4,11}$ The literature reports of preceptors requiring adequate time to execute the preceptorship and administrative roles apart from caring for patients.

Preceptors further required support from their colleagues within their health facilities as well as members of faculty from the hosting institutions that sent students for clinical practice. Once this was provided, the preceptors would be able to fulfil the roles of patient care and clinical teaching with ease. As noted by Duteau, ${ }^{1}$ preceptor's workload, lack of support from peers, and overall lack of support from faculty members negatively affected their roles as preceptors. Concurring with this observation, the study found that some faculty members did not involve or engage preceptors whenever they visited the institutions for supervision and clinical teaching. The preceptors felt that this was a sign of disregard to them and their contributions. Preceptors then expressed the need for working as a team with faculty members every time they visited the 
clinical area for supervision and clinical teaching. Broadbent et $\mathrm{al}^{7}$ reported similar findings that lack of support from the universities and colleges that placed students in the clinical sites created difficulties during clinical placement. Thus, lack of joint working relationship with faculty members made it hard for the preceptors to continue from where the faculty members left in clinical teaching and supervision. As noted by Kalischuk et al, ${ }^{4}$ lack of support from nursing faculty members, makes it difficult for the preceptorship goals to be met. Therefore, there was need for faculty members to create good working relationships with the preceptors for the benefit of the students.

This study has revealed that following up students in the clinical areas was a challenge due to shortage of trained preceptors. The findings indicated a huge preceptor-student ratio rendering the preceptorship role tedious and nonproductive. Beyond this, shortage of trained preceptors led to increased workload on the available few preceptors. This contributed to making preceptorship ineffective as similarly reported by previous studies. ${ }^{10}$ The problem of lack of adequate preceptors could be attributed to lack of preceptorship trainings as some nurses who were trained as preceptors either died or left bedside nursing. Therefore, a significant number of registered nurses currently practicing are yet to be trained in preceptorship.

\section{Study Strengths and Limitations}

The use of participants with a minimum of three years' experience as a preceptor for undergraduate students was considered as a strength since they were well vested with the preceptorship challenges. The study settings covered the three regions of Malawi, indicating that the results reflected the opinions of preceptors across Malawi. However, the study results may have been affected by participants' recall bias as participants were asked things or issues that happened sometime back, and this should be taken as a study limitation when considering these results.

\section{Conclusion}

It was concluded that preceptors in Malawi experience challenges such as lack of support from faculty and colleagues who are not trained preceptors as well as inadequate numbers of trained preceptors against an increased number of nursing students. These challenges end up piling pressure on the available preceptors as they cannot cope with the student numbers as well as their double binding roles which combines patient care and clinical teaching. There is a need therefore to improve the working relationships between the preceptors, faculty members and workmates who are not preceptors in order to enhance effective clinical learning and teaching experiences among nursing students. This could be effected through joint meetings where the members can be informed of the roles of preceptors and the need for collaborative efforts in clinical teaching. Furthermore, the available registered nurses should be encouraged to enrol and be trained as preceptors to increase the number of nurses who can competently teach students within the clinical sites. Nursing colleges should agree and put together financial resources and provide scholarships to practicing registered nurses for them to be trained as preceptors. This is because preceptors teach students from all the training institutions. There is also a need to engage nurses not trained as preceptors to change their mindset and begin to work with their colleagues in supporting nursing students during clinical practice. Research should further be conducted to further investigate the working relationship between preceptors and faculty members whose findings may assist to improve collaboration to enhance clinical teaching.

\section{Acknowledgments}

The authors acknowledge the preceptors who voluntarily took part in the study.

\section{Disclosure}

The authors report no support or sponsorship from any institution and no conflicts of interest in this work.

\section{References}

1. Duteau J. Making a difference: the value of preceptorship programs in nursing education. $J$ Contin Educ Nurs. 2012;43(1):37-43. doi:10.3928/00220124-20110615-01

2. Atakro CA, Gross J. Preceptorship versus clinical teaching partnership: literature review and recommendations for implementation in Ghana. Adv Nurs. 2016;2016.

3. Rachael Vernon RN. A critical review of preceptor development for nurses working with undergraduate nursing students. Int J Caring Sci. 2017;10(2):1089.

4. Kalischuk RG, Vandenberg H, Awosoga O. Nursing preceptors speak out: an empirical study. J Prof Nurs. 2013;29(1):30-38. doi:10.1016/j. profnurs.2012.04.008

5. O'Neil M, Jarrah Z, Nkosi L, et al. Evaluation of Malawi's emergency human resources programme. 2010.

6. McCarthy B, Murphy S. Preceptors' experiences of clinically educating and assessing undergraduate nursing students: an Irish context. $J$ Nurs Manag. 2010;18(2):234-244. doi:10.1111/j.1365-2834.2010.01050.x

7. Broadbent M, Moxham L, Sander T, Walker S, Dwyer T. Supporting bachelor of nursing students within the clinical environment: perspectives of preceptors. Nurse Educ Pract. 2014;14(4):403-409. doi:10.1016/j.nepr.2013.12.003 
8. Löfmark A, Thorkildsen K, Raaholm M-B, Natvig GK. Nursing students' satisfaction with supervision from preceptors and teachers during clinical practice. Nurse Educ Pract. 2012;12(3):164-169. doi:10.1016/j.nepr.2011.12.005

9. Omansky GL. Staff nurses' experiences as preceptors and mentors: an integrative review. $J$ Nurs Manag. 2010;18(6):697-703. doi:10.1111/j.1365-2834.2010.01145.x

10. Monareng LV, Jooste K, Dube A. Preceptors' and preceptees' views on student nurses' clinical accompaniment in Botswana. Afr J Nurs Midwifery. 2009;11(2):113-127.

11. O'Brien A, Giles M, Dempsey S, et al. Evaluating the preceptor role for pre-registration nursing and midwifery student clinical education. Nurse Educ Today. 2014;34(1):19-24. doi:10.1016/j. nedt.2013.03.015

12. Phuma-Ngaiyaye E, Bvumbwe T, Chipeta MC. Using preceptors to improve nursing students' clinical learning outcomes: a Malawian students' perspective. Int $J$ Nurs Sci. 2017;4(2):164-168. doi:10.1016/j.ijnss.2017.03.001
13. Hunter D, McCallum J, Howes D. Defining Exploratory-Descriptive Qualitative (EDQ) research and considering its application to healthcare. J Nurs Health Care. 2019;4(1).

14. Creswell JW, Creswell JD. Research Design: Qualitative, Quantitative, and Mixed Methods Approaches. Sage publications; 2017.

15. Grove SK, Burns N, Gray J. The Practice of Nursing Research: Appraisal, Synthesis, and Generation of Evidence. 7th ed. Elsevier Health Sciences; 2017.

16. Polit DF, Beck CT. Nursing Research: Generating and Assessing Evidence for Nursing Practice. Lippincott Williams \& Wilkins; 2014.

17. Tong A, Sainsbury P, Craig J. Consolidated criteria for reporting qualitative research (COREQ): a 32-item checklist for interviews and focus groups. Int J Qual Health Care. 2007;19(6):349-357. doi:10.1093/intqhe/mzm042

18. Braun V, Clarke V. Using thematic analysis in psychology. Qual Res Psychol. 2006;3(2):77-101. doi:10.1191/1478088706qp063oa

\section{Publish your work in this journal}

Advances in Medical Education and Practice is an international, peerreviewed, open access journal that aims to present and publish research on Medical Education covering medical, dental, nursing and allied health care professional education. The journal covers undergraduate education, postgraduate training and continuing medical education including emerging trends and innovative models linking education, research, and health care services. The manuscript management system is completely online and includes a very quick and fair peer-review system. Visit http://www.dovepress.com/testimonials.php to read real quotes from published authors. 